\title{
Phase 1 Space Fission Propulsion System Testing and Development Progress
}

\author{
Melissa Van Dyke ${ }^{1}$, Mike Houts ${ }^{1}$, Tom Godfroy ${ }^{1}$, Ricky Dickens ${ }^{1}$, David Poston ${ }^{2}$, \\ Rick Kapernick ${ }^{2}$, Bob Reid ${ }^{2}$, Pat Salvail ${ }^{3}$, Peter Ring ${ }^{4}$
}

${ }^{\prime}$ Marshall Space Flight Center, National Aeronautics and Space Administration, Huntsville, Alabama, 35812

${ }^{2}$ Los Alamos National Laboratory, University of California, US Department of Energy, PO Box 1663, MS J576, Los

Alamos, New Mexico 87545

${ }^{3}$ ITT Research Institute, Marshall Space Flight Center, National Aeronautics and Space Administration, Huntsville, Alabama, 35812

${ }^{4}$ Advanced Methods and Materials, 510 Lawrence Expressway, Suite 203, Sunnyvale, California, 94086

(256) 544-5720, Melissa.Vandyke@msfc.nasa.gov

\begin{abstract}
Successful development of space fission systems requires an extensive program of affordable and realistic testing. In addition to tests related to design/development of the fission system, realistic testing of the actual flight unit must also be performed. If the system is designed to operate within established radiation damage and fuel burn up limits while simultaneously being designed to allow close simulation of heat from fission using resistance heaters, high confidence in fission system performance and lifetime can be attained through a series of non-nuclear tests. The Safe Affordable Fission Engine (SAFE) test series, whose ultimate goal is the demonstration of a $300 \mathrm{~kW}$ flight configuration system, has demonstrated that realistic testing can be performed using non-nuclear methods. This test series, carried out in collaboration with other NASA centers, other government agencies, industry, and universities, successfully completed a testing program with a $30 \mathrm{kWt}$ core, Stirling engine, and ion engine configuration. Additionally, a $100 \mathrm{kWt}$ core is in fabrication and appropriate test facilities are being reconfigured. This paper describes the current SAFE non-nuclear tests, which includes test article descriptions, test results and conclusions, and future test plans.
\end{abstract}

\section{INTRODUCTION AND BACKGROUND}

Successful development of space fission systems will require an extensive program of affordable and realistic testing. In addition to tests related to the design/development of the fission system, realistic testing of the actual flight unit must also be completed. Because heat from fission cannot be used for full-power testing of flight units (due to radiological activation), space fission systems must be designed such that heat from fission can be very closely mimicked by some other means. While some nuclear testing will be required, the system will ideally be optimized to allow maximum benefit from non-nuclear testing during the development phase.

Non-nuclear tests are affordable and timely, and the cause of component and system failures can be quickly and accurately identified. The primary concern with non-nuclear tests is that nuclear effects are obviously not taken into account. To be most relevant, the system undergoing non-nuclear tests must thus be designed to operate well within demonstrated radiation damage and fuel burn up capabilities. In addition, the system must be designed such that minimal operations are required to move from non-nuclear testing mode to a fueled system operating on heat from fission. If the system is designed to operate within established radiation damage and fuel burn up limits while simultaneously being designed to allow close simulation of heat from fission using resistance heaters, high confidence in fission system performance and lifetime can be attained through a series of non-nuclear tests. Any subsequent operation of the system using heat from fission instead of resistance heaters would then be viewed much more as a demonstration than a test - i.e. the probability of system failure from nuclear effects would be very low. These types of systems, along with any other nuclear propulsion system that can be tested with existing nuclear facilities, can be characterized as Phase 1 systems. 
In order to address some of the Phase 1 space fission system issues, MSFC is leading a Safe Affordable Fission Engine (SAFE) test series. This test series is carried out in collaboration with other NASA centers, other government agencies, industry, and universities. Figure 1 shows the SAFE series of non-nuclear test programs that ultimately leads to the (non-nuclear) demonstration of a $400 \mathrm{~kW}$ (refractory metal core) flight configuration system. The MUTT test series and the $30 \mathrm{~kW}$ core tests were presented in a previous paper at the STAIF conference in 2001 (Van Dyke and Houts, 2001). This paper will concentrate on the end-to-end demonstrator, the $100 \mathrm{~kW}$ and the $400 \mathrm{~kW}$ core. While this paper covers overall program objectives, detailed test results and manufacturing techniques can be found in separate papers at the STAIF 2002 conference.

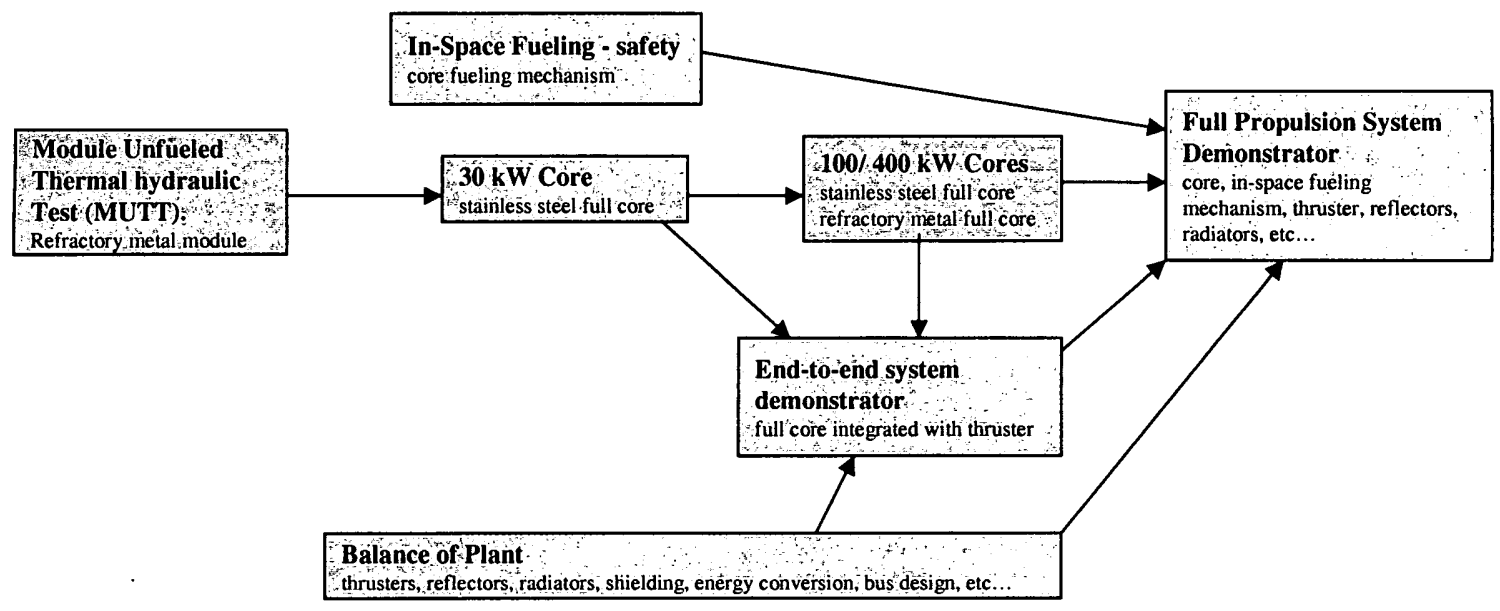

FIGURE 1. The Safe Affordable Fission Engine (SAFE) Test Program.

\section{END-TO-END SYSTEM CONCEPT DEMONSTRATION}

The SAFE 30 test series was a full core test capable of producing $30 \mathrm{~kW}$ using resistance heating to simulate the heat of fission. The $30 \mathrm{~kW}$ core consists of 48 stainless steel tubes and 12 stainless steel/sodium heat pipes $(2.54 \mathrm{~cm}$ diameter, $119 \mathrm{~cm}$ length) welded together longitudinally to formulate a core similar to that of a fission flight system. Heat is removed from the core via the heat pipes. A solid copper block is attached to three of the heat pipes and serves as a heat exchanger for the off-the-shelf Stirling engine from the Stirling Technology Corporation (STC). While the core and heat pipes are prototypic of an actual flight system and were optimized for performance, the heat exchanger and conversion system were not. The purpose of the end-to-end tests was to show proof-of-concept with inexpensive off-the-shelf materials in a relevant environment. More flight prototypic heat exchangers are being pursued in the SAFE 100 and SAFE 400 testing series. Output from the Stirling engine is fed to a DC/DC converter where the voltage and current are conditioned to provide the right operating parameters from the ion engine (from $100 \mathrm{~V}$ to $1000 \mathrm{~V}$ ). The ion engine is a $15-\mathrm{cm}$ diameter ion engine developed at JPL that incorporates several advanced ion engine technologies such as carbon-carbon ion optics (Brophy, 1993 and Mueller, 1994). For the SAFE 30 tests, the Stirling engine output is fed to the grid, while discharge and neutralizer cathode will be run with laboratory power supplies.

After demonstration of the Stirling engine at $300 \mathrm{~W}$ using the SAFE30 both in a vacuum and $\mathrm{CO} 2$ environment at MSFC, the assembly was shipped to the Jet Propulsion Laboratory, where it was reassembled and tested to verify performance. The Stirling engine control board was shipped back to STC for modification to accommodate the change in the end load (ion engine instead of a resistive load). The DC/DC converter arrived at JPL in September 2001. After some initial checkout tests are performed, it is expected that the integration can be completed by Oct/Nov 2001. This will be the first time in the U.S. that a hardware ground based system of an entire concept (core, energy conversion and an electric propulsion engine) will be demonstrated. Figure 2 shows the core / heat pipe / Stirling engine assembly at JPL. Figure 3 shows the ion engine mounted on the vacuum chamber door above the SAFE 30 core assembly. 


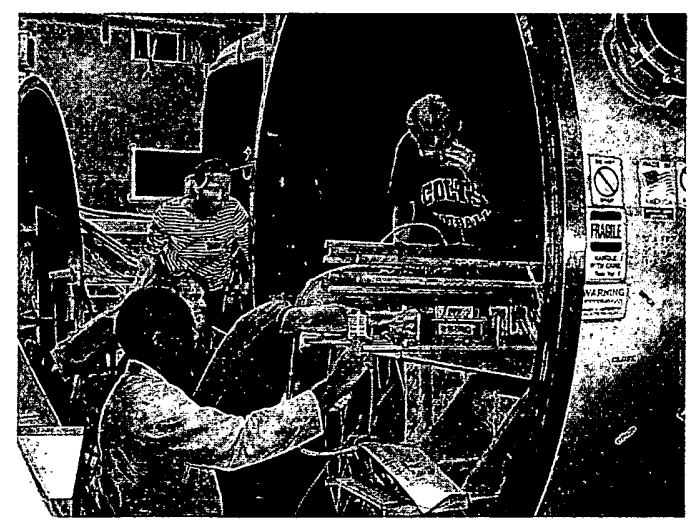

FIGURE 2. SAFE30 Test Article at JPL.

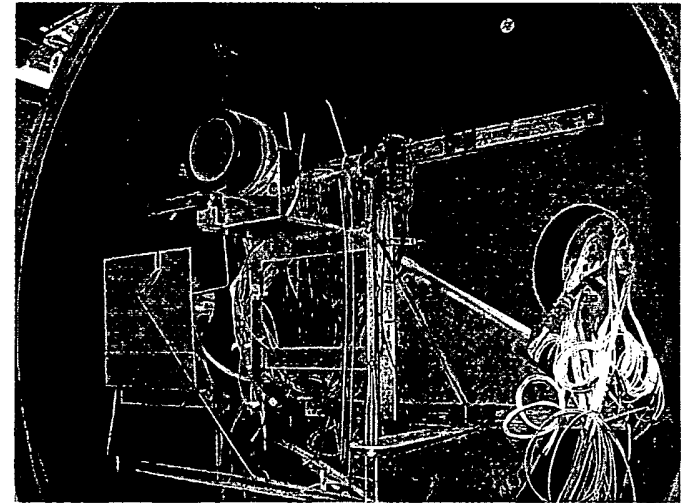

FIGURE 3. Electric Propulsion Ion Engine Integrated to the SAFE 30.

\section{SAFE100}

While the SAFE 30 demonstrated that resistance-heating techniques could be used for an entire core (versus a module), it also shed light on some testing issues that would be less expensive to solve using another stainless steel core, rather than jumping straight to a refractory metal core. The refractory metal core pin size is half the size of the SAFE 30, making electrical hook-up, power control, and heater design much more difficult than the SAFE 30. The SAFE 30 demonstrated that the heat exchanger design is best done simultaneously with the core design, rather than "throwing it over the fence". The SAFE 30 demonstrated only one possible technique (brazing) for module manufacturing. Finally, The SAFE 30 demonstrated the need for the ability of "mass-production" of heat pipes.

The next core in the MSFC phase 1 testing series is the SAFE 100. This core is designed to deliver $100 \mathrm{~kW}$ (thermal) to the heat pipes and is constructed from 316 stainless steel using geometry similar to the SAFE 400 (refractory metal) design. Originally, the core was designed to be an exact geometric duplicate to the refractory metal core, however, a change in mission requirements altered the refractory metal core design during the manufacturing and build-up of the SAFE 100. All the lessons learned in the SAFE 100 are directly applicable to the updated refractory metal core design and it is not anticipated to build another "stepping stone" core between the SAFE 100 and the SAFE 400 (updated refractory metal core design). Keeping the lessons learned in the SAFE 30 in mind, the SAFE 100 is to accomplish the following specific objectives:

- Investigation of manufacturing techniques (e.g. HIP) for module and core assembly

- Core support systems including design and development of a flight like prototypic core strapping structure

- Provide updates to thermal codes including modeling of appropriate insulation boundary around core to simulate radial reflectors, thermal performance, and thermal cycling effects (fatigue/ strain)

- Design and fabrication of prototypic heat exchanger (from heat pipe to HX gas inlet). Demonstrate ability of prototypic heat exchanger to remove at least $90 \%$ of energy from heat pipes.

- Demonstrate ability of MSFC manufactured heaters to provide sinusoidal temperature and power profile for over 75 tests (Heaters are conservative due to radiative coupling and absence of conduction through heaters).

- Demonstration of a 32 "hands-off" control zone system to match radial core power profile. Heater design matches axial power profile

- Development and demonstration of stainless steel heat pipe fill and cap capability at MSFC

- Gain hardware-based insight into other required design attributes of more advanced space fission systems., including investigation of expansion characteristics for various core design options 
- Demonstrate ability of the core to efficiently transfer heat from the fuel elements to a point external to the core via heat pipe. Demonstrate a heat pipe transfer rate of greater than $1 \mathrm{~kW}$ (the heat pipes used are rated for $20 \mathrm{~kW}$ at an evaporator exit operating temperature of $700 \mathrm{deg} \mathrm{C}$ )

- Demonstrate performance of core heat pipe system operating in CO2 at 6 to 12 torr (major constituent of Mars atmosphere)

The power and control system for the SAFE 100 was designed utilizing all the lessons learned from the SAFE 30 . The SAFE 30 tests showed that to avoid voltage break down, voltage in the chamber must be kept extremely low. The SAFE 30 also showed the need for an integrated power and control system, while at the same time, giving the flexibility of controlling every heater at the wattage level. The power system for the SAFE series is designed around the ability to operate in a gas ( $\mathrm{CO} 2$ and $\mathrm{GHe}$ ) environment while still maintaining a large number of control zones capability. The power supply to the core is delivered through thirty-two $150 \mathrm{vdc} 100 \mathrm{amp}$ power supplies, with a total power output capability of $400+\mathrm{kw}$. A balance voltage and current is maintained at "low" levels that allow gasses to be introduced into the chamber without having to worry about voltage breakdown effects (corona) on the electrical heaters. The power supplies are controlled by 32 Programmable Logic Controllers (PLCs) which have the ability to shut down any one power supply if an error is detected. Commands to the PLCs are sent from the Human Machine Interface (HMI), and the HMI can send all the outputs to zero from one emergency stop button as an added facility safety precaution. The HMI can fail and the power supplies will remain at the last known value, unless as above, an error is detected. The power to the supplies and the PLCs come from experiment power this is to insure a lost of power does not effect control.

Power is controlled by a combination of hardware and software applications. A fuzzy-logic controller regulates output power resolution across the full operating range through the HMI (software integration). Although load power is maintained by changing the dynamic variables, i.e. HMI voltage/current set points, the controller also features power profile mapping. A number of radial nuclear power profiles, from flat to cosine distributions are possible. Control features also allow for simplified operator interface controls, slow warm-up, data logging, etc. Particular attention in the development of the fuzzy logic algorithm ensures that the system process remains at set point, virtually eliminating overshoot on start-up and during in-process disturbances. The graphite heaters are shaped to demonstrate the ability of producing an axial power profile. The integrated control system (HMI, PLC, power supply, and fuzzy logic controller) was demonstrated through different power levels at a module level in September 2001 .

Since each resistance heater for the SAFE-100 was designed to be used in the first refractory metal core design (SAFE 300), each heater must be capable of providing $1450{ }^{\circ} \mathrm{C}$ and $1.5 \mathrm{~kW}$ or better per heater. Each heater must also be capable of providing an axial power profile. Manufacturing of these heaters is extremely difficult due to the close proximity of the electrical connectors due the small diameter requirement of $(0.95-1.27 \mathrm{~cm})$ of the heater. Several configurations were investigated, including the use of graphite elements with boron nitride and alumina coatings. The heater design chosen for the SAFE 100 was a shaped poco graphite.material with alumina insulators and copper connecters. Alumina and copper were chosen for the SAFE 100 for cost reasons. A different insulator and connector, whose performance has already been demonstrated, will be used for the refractory metal module.

While SAFE 30 demonstrated the brazing technique for module manufacturing, the SAFE 100 will use a Hot Isostatic Pressing (HIP) process. In designing the SAFE Heat pipe reactor, it is highly desirable that the interstices between the fuel tubes and between the fuel tubes and the heat pipes, are filled. The SAFE 30 modules were brazed together using a tricusp insert in the gaps between tubes to ensure maximum braze coverage. The SAFE 100 modules are planned to be diffusion bonded together using a HIP process. Although the complex geometry of the SAFE 100 is quite challenging to fabricate by diffusion bonding, it was considered worth the effort. If successful, the HIP technique will produce an assembly with the heat pipe completely embedded within the module and the module will have thermal conduction and strength equivalent to a solid structure. Although brazing was used very successfully for the SAFE 30, it does have some disadvantages: braze joints are not as strong as diffusion bonds, braze joints rarely provide $100 \%$ joint coverage, and braze joints are difficult to inspect non-destructively. Additionally, developing a satisfactory braze method for refractory metals will be quite difficult whereas once the mechanics of the HIP method have been successfully developed for the stainless steel SAFE 100, it should be fairly easy to transpose the tooling and methodology to a refractory system. 
The SAFE 100 provides additional test data to better benchmark both thermal and structural codes and models as well as provide design guidance for the refractory metal core. The SAFE-100 analysis is based upon a reactor design core which assumes UN fuel with a small gap filled with helium between the UN fuel and fuel clad. With this design, there is considerable potential for heat transfer through the fuel, which acts to reduce temperature gradients in the modules and attendant thermal stresses. In the non-nuclear test core, graphite resistance heaters are placed in the fuel channels. Although graphite is a good conductor, the tests are run in a vacuum, and there is little heat transfer across the gaps between the heaters and fuel clad. Because of this difference (between the design core and test core), calculated peak temperatures and thermal stresses in the test core operating at $25 \mathrm{~kW}$ are about equal to those in the design core at $100 \mathrm{~kW}$. The first few tests performed on the SAFE 100 (non nuclear) will be at a $25 \mathrm{~kW}$ power level. Based on analysis performed for the test model, it is expected that the fuel clad will yield and undergo stress relaxation when operated at $100 \mathrm{~kW}$, but that the plastic strains will be very small and well within the allowable strain range for SS-316.

\section{SAFE400}

While efforts are underway to modify facilities to test the $100 \mathrm{~kW}$ core, as well as the manufacturing of the actual test article, small test efforts and design studies are underway to prepare for the SAFE 400 test series.

The first refractory metal core design was designed around the requirement of producing $100 \mathrm{~kW}$ electric. The SAFE $300(\mathrm{~kW}$ thermal) core assumed an electrical conversion efficiency of $33 \%$. Recent design studies and mission requirements have modified the core design due to a change in assumed electrical conversion efficiency from $33 \%$ to $25 \%$. The refractory metal core must be capable of $400 \mathrm{~kW}$ thermal in order to produce $100 \mathrm{~kW}$ electric. Although the basic heat pipe concept is the same, small trade studies are being performed by Los Alamos to determine the optimum design. Trade offs include fuel type and clad material.

Additionally, heater requirements have changed over the past few years. While the first set only required the heaters to match the maximum temperature in the core, the requirements changed due to the success in heater development and in the need for the heaters to better match actual flight profile (based on the results of earlier tests). This includes matching power densities (axial and radial) and heat transfer mechanisms to the best ability that can be achieved through non-nuclear testing. Although the heaters developed for the SAFE 100 can be modified to achieve power profiles, efforts are underway to look at a new heater design to see if it can better match the actual heat transfer mechanism within the pin/clad.

Small laboratory experiments are being performed at module levels to experiment with and work out issues with the test core. For example, the power delivery set-up for the SAFE 100 and SAFE 400 cores are tested at 1/32 of the actual unit itself (test 1 zone rather than 32). Different shielding options for heater hook-up are being investigated to minimize thermal losses through the front of the core. Different insulation techniques to be used on the test cores are tested at module levels for effectiveness rather than trying each technique on the core itself. These types of tests allow for issues to be resolved at a less complex and less costly level than on the test core itself.

Current objectives of the SAFE 400 test series include:

- Demonstrate that the performance of the core is very close to flight prototypic for an NEP system of 80-100 $\mathrm{kW}$ electric.

- Investigate instrumentation and update power delivery (if needed)

- Match radial core power profile. Match axial power profile

- Heater development program - more closely simulate actual heat transfer mechanism in pin/clad

- Refractory metal heat pipe fill and cap capability at MSFC

- Investigate module geometry, heat exchangers, etc.. - refractory metal core

- Investigate expansion characteristics for various core design options

- Prototypic heat exchanger design (from heat pipe to HX gas inlet)

- Finalize module geometry and fabrication with refractory metal

- Investigate core support systems

- Investigate thermal cycling effects (fatigue/ strain) through multiple testing 
- Validate thermal performance

\section{CONCLUSIONS}

Full power nuclear tests of space fission systems are expensive, time consuming, and of limited use, even in the best of programmatic environments. Non-nuclear tests are affordable and timely, and the cause of component and system failures can be quickly and accurately identified. If the system is designed to operate within established radiation damage and fuel burnup limits while simultaneously being designed to allow heat from fission to be closely mimicked using other methods, high confidence in fission system performance and lifetime can be attained through a series of non-nuclear tests. In addition, realistic testing of actual space fission system flight units can be performed.

In order to address some of the first generation system issues, MSFC is leading the SAFE test series. This test series is carried out in collaboration with other NASA centers, other government agencies, industry, and universities. Programs either tested, or currently undergoing testing, include refractory metal modules, heat pipes, high temperature heaters, stainless steel cores, and end-to-end demonstrators and in-space fueling.

\section{REFERENCES}

Brophy, J.R., Pless, L.C., Mueller, J.M., and Anderson, J.R., "Operating Characteristics of a 15-cm dia. Ion Engine for Small Planetary Spacecraft," IEPC-93-110, 23rd International Electric Propulsion Conference, Seattle, WA, Sept. 1993.

Mueller, J.M., Brophy, J.R., Brown, D.K., and Garner, C.E., "Performance Characterization of 15-cm. Carbon-Carbon Composite Grids," AIAA-94-3118, 30th Joint Propulsion Conference, Indianapolis, IN, June 1994.

Van Dyke, M., Houts, M., Pedersen, K., Godfroy, T., Dickens, R., Poston, D., Reid, B., Salvail, P.,Ring, P., "Phase 1 Space Fission Propulsion System Testing and Development Progress," STAIF-2001, Albuquerque, N.M., Feb 2001. 